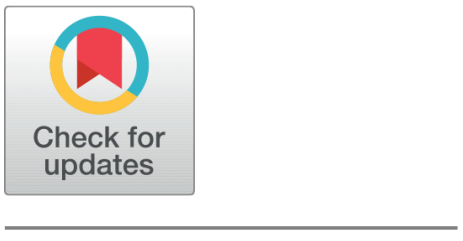

OPEN ACCESS

Received: 14.09.2021

Accepted: 03.12.2021

Published: 27.12 .2021

Citation: Moctar M, Ky TSM, Konfé A, Dianda B, Ouédraogo $S$, Bathiébo DJ (2021) Natural Convection Modeling in a Solar Tower. Indian Journal of Science and Technology 14(48): 3475-3493. https://doi.org/

10.17485/IJST/v14i48.1357

* Corresponding author.

ousmane.m2001@gmail.com

Funding: None

Competing Interests: None

Copyright: (c) 2021 Moctar et al. This is an open access article distributed under the terms of the Creative Commons Attribution License, which permits unrestricted use, distribution, and reproduction in any medium, provided the original author and source are credited.

Published By Indian Society for Education and Environment (iSee)

ISSN

Print: 0974-6846

Electronic: 0974-5645

\section{Natural Convection Modeling in a Solar Tower}

\author{
Moctar Moctar ${ }^{1 *}$, Thierry Sikoudouin Maurice Ky², Amadou Konfé2, \\ Boureima Dianda ${ }^{3}$, Salifou Ouédraogo², Dieudonné Joseph Bathiébo ${ }^{2}$ \\ 1 University of Agadez, PO BOX 199, Niger \\ 2 Laboratory L.E.T.R.E, University Joseph KIZERBO, PO BOX 7021, Ouagadougou 03, Burkina \\ Faso \\ 3 Institute of Research in Applied Science and Technologies, Ouagadougou 03, PO Box 7047, \\ Burkina Faso
}

\begin{abstract}
Objectives: We present in this study a modeling of thermal laminar convection airflow in a solar tower. Methods: To formulate with precision, the boundary conditions of the solar chimney model chosen, the Cartesian equations are transformed into hyperbolic coordinates. An orthogonal grid is elaborated. It then makes it possible to draw up the diagrams of physique and calculation fields. The computer code uses the heat equation, the vorticity, and the stream function formalism as the boundary conditions for pressure are difficult to set. We use the Boussinesq approximation, which consists in considering that the density $(\rho)$ of the fluid varies only in the term of the gravity forces, whose variations with temperature, assumed to be linear, generate natural convection. These variations are then translated into an equation of state which relates density to temperature. The system of dimensionless equations is solved by using an intégro-interpolation method referring to finite differences scheme. Findings: The solutions obtained from the dimensionless equations enabled us to determine the space evolution parameters (temperatures and velocities) in the tower according to the Rayleigh number. The fluid temperature and velocity evolution in the collector increase when one moves in the direction of radius decrease. The fluid temperature evolution in the chimney showed that the highest temperature is located at the chimney base while we obtained a parabolic profile of the transverse temperature distribution within the chimney. Finally, the evolution of the fluid velocity in the chimney showed that there was a preferred zone for turbine installation. Novelty : The use of dimensionless geometric parameters is unique and in general, the approach adopted in this paper differs from that encountered in the literature.
\end{abstract}

\section{Introduction}

Nowadays, the development level of each nation is measured by the rate of access to electricity and its consumption per capita. In our countries, the energy crisis, the deterioration of the environment, and the decline in agricultural yields have negative consequences on the quality of life. The population growth and development needs have led to an increase in the consumption of traditional energy resources. Indeed, in 
developing countries, outside of urban centers, electric power is non-existent. Paradoxically, these countries are characterized by a hot and dry climate coupled with intense and regular sunshine. With large areas and reported to at least an average daily solar energy of $5.5 \mathrm{kWh} / \mathrm{m}^{2}$.day to $6.5 \mathrm{kWh} / \mathrm{m}^{2}$.day; and duration from 3000 to 3500 hours per year we immediately understand that this tremendous, "free", non-polluting, almost inexhaustible energy potential can cover a large part of the energy needs of our countries [1]. It is with this in mind that researchers and policymakers have turned to renewable energies. Thus, the solar chimney introduced by Jörg Schlaich and Rudolf Bergermann [2] in 1976 is a new technology for producing electricity by transforming solar energy into mechanical energy. Figure 1 shows the description of a solar chimney power plant as consisting of a collector, a turbine, and a vertical chimney given by Isidoro Cabanyes in 1903. In 1926, Bernard Dubos [3] proposed to use a vertical wind blowing in a tube on the side of a mountain as a solar chimney.

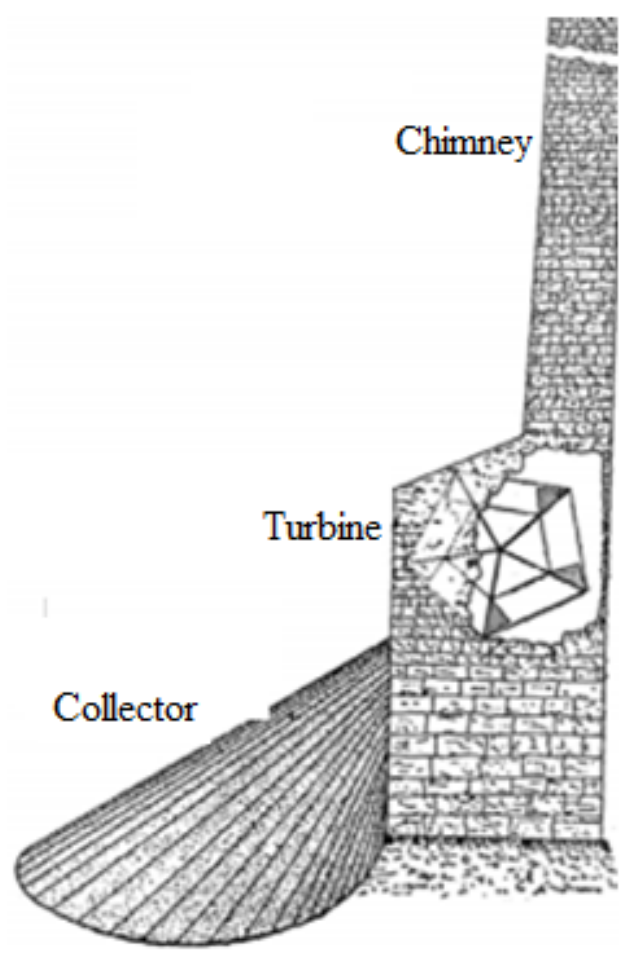

Fig 1. Solar chimney power plant project proposed by Isidoro Cabanyes [4]

Figures 2 and 4 show respectively between 1940 and 1960, then in 1975, two solar tower projects close to each other studied by Edgard Nazaré [4] and Louis Michaud.

Finally, faced with these different original concepts, Figure 4 shows the first prototype tower built in 1981 thanks to the team of Pr J. Schlaich, in Spain. The first experimental model is that of Manzanares which operated from 1982 to 1989 (J. Schlaich) [2,5]. This tower served as an information provider [6].

Pasumarthi and Scherif $[7,8]$ built a conical solar tower in Florida. This study reviewed the heat transfer within the collector and the possibilities to improve it. In China, a pilot plant with an energy storage system was built [9,10]. Likewise, in Brazil [1113], a solar tower was built. Koyun et al, Buğutekin et al [14,18], built two pilot plants. Golder et al, Akbarzadeh et al [15,16], built a hybrid system consisting of a solar power plant associated with a solar pool. Ahmed et al [17], built a prototype which made it possible to study the influence of the nature of the soil on the temperature profile of the chimney. Najmi et al, Kasaeian et al $[19,20]$ built prototypes with a cone at the entrance of the chimney to improve the power output and decrease the height of the air inlet. Mehla et al, Shuia et al, Al-Dabbas [21-23] developed prototypes in which they reviewed the influence of geometric parameters and their variation with solar radiation. Chappell et al [24] designed a prototype solar chimney at low material cost and technically less cluttered. Figure 5 shows four experimental prototypes in which experimental results differ from one model to another, nevertheless, have the same appearance as the simulated results developed by Koonsrisuk et al [25]. 


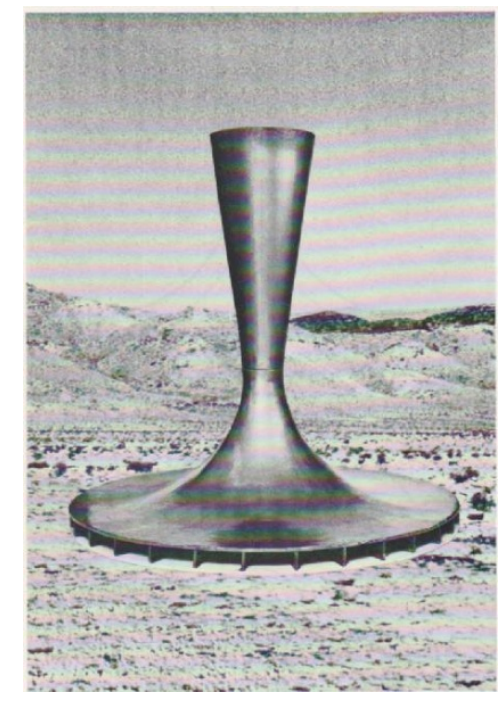

Fig 2. Nazaré aerothermal power plant [4]

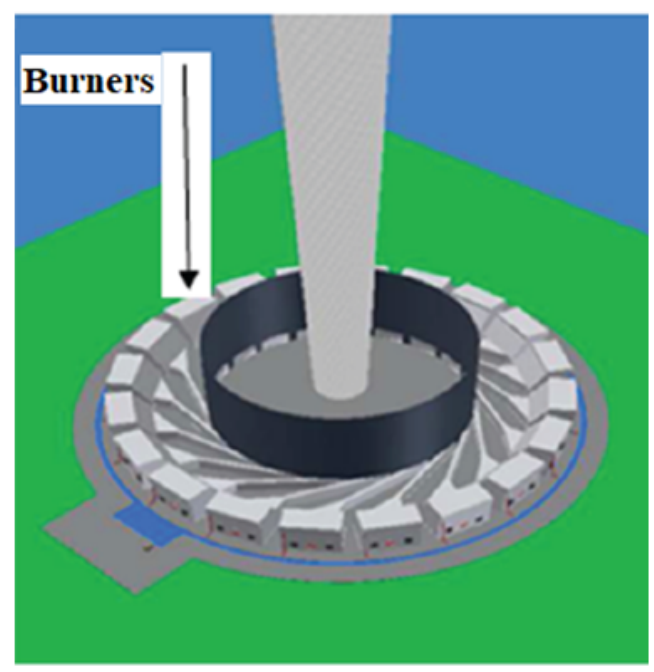

Fig 3. Michaud type aerothermal power plant [4]

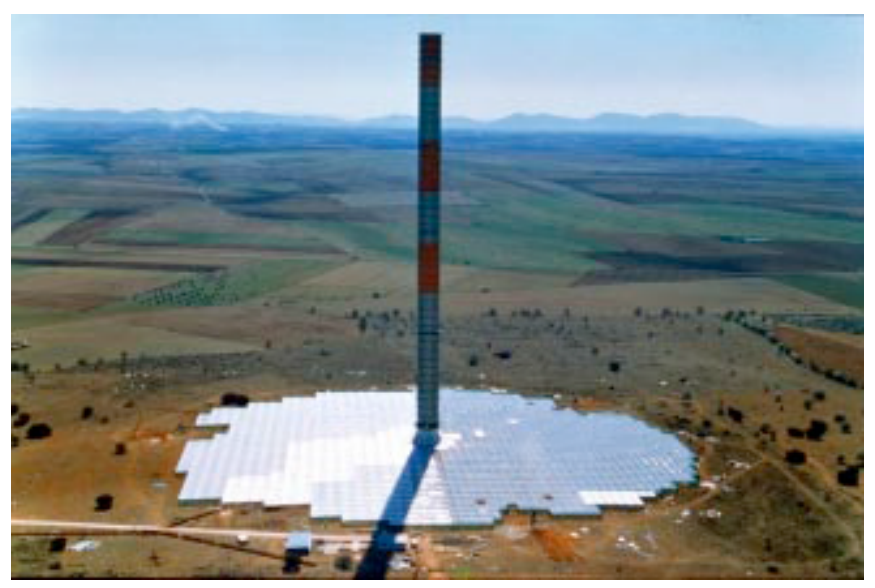

Fig 4. Prototype of the solar tower prototype plant at Manzanares, Spain [6] 

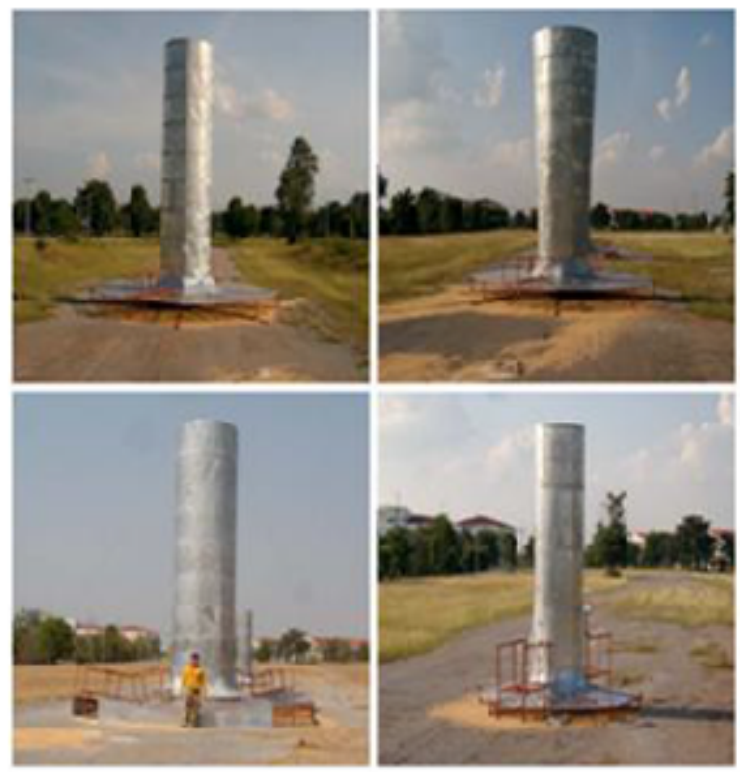

Fig 5. Experimental prototypes in Thailand [4]

Aja et al [26] showed that there is a preferred direction and orientation for which the velocity and direction of the wind strongly impact on the performance of the prototype. An experimental prototype of a solar chimney was designed at the Laboratory of Renewable Thermal Energies of Ouagadougou University, (Burkina-Faso) [1] which revealed that at the chimney entrance the absorber's temperature decreases slightly while that of the fluid is maintained at a maximum level. An increase in the stack height results in an intensification of convective movements within the prototypeWe also notice an increase in the fluid's temperature at the expense of that of the absorber. The maximum velocities are obtained at the chimney entrance but decrease very quickly along the ascending axis of the latter. Flow can be improved in this area by using curved junctions. Figure 6 shows the experimental prototype of Ouagadougou's university.

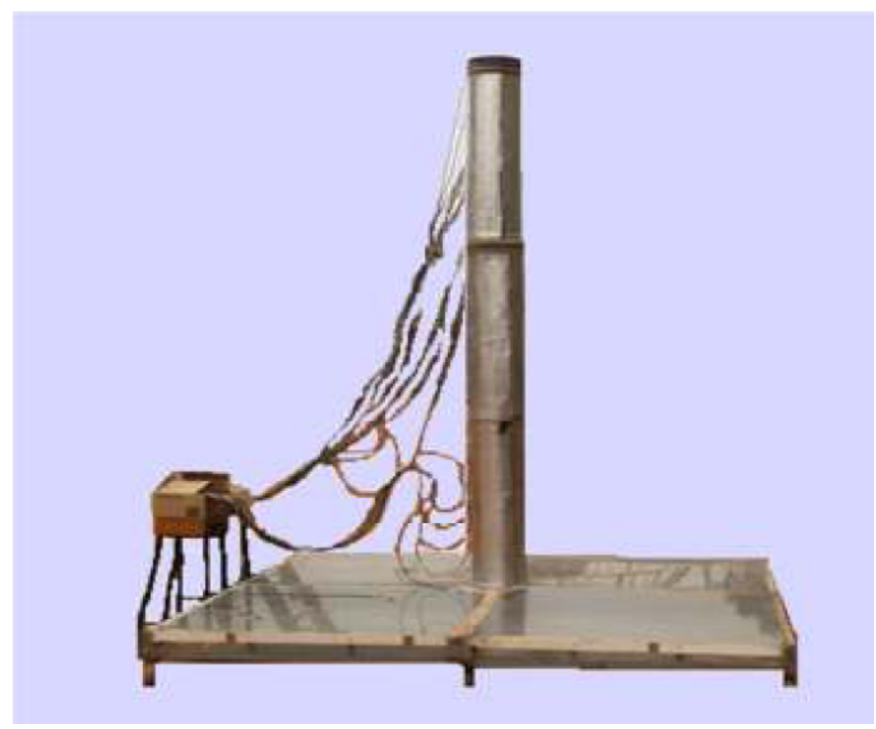

Fig 6. Experimental prototype of Ouagadougou's nuiversity [1] 
This confirms the choice of this zone, by several authors for the turbine installation. The ideal location for the drying racks is the area above the chimney entrance, characterized with relatively high temperatures and maximum flow velocities. These conditions are favorable to mass and heat transfers. This study confirms the feasibility of the system but also highlights the need to optimize the thermo-aeraulic parameters to produce electricity and allow the conservation of food products. Al-Azawie et al, Li et al, Tan et al [27-29] studied, experimentally the conversion capacity of materials then the contribution of phase change materials, and finally the effects of the ambient air velocity and the internal thermal load on the solar chimney. Shahreza et al [30] brought an innovation in the design of a solar tower by associating concentrators able to track the sun. The maximum velocity obtained then reached $5.12 \mathrm{~m} . \mathrm{s}^{-1}$. This is especially important about the dimensions of the prototype. Ghalamchi et al [31] developed a solar chimney pilot plant and concluded that reducing the collector inlet height increases the performance of the system. During the same year, Okada et al [32] experimented with two types of chimneys: one in the shape of a cylinder and another in the shape of a diffuser. They proved that the diffuser-shaped chimney increases the air speed resulting in better power output than in the cylindrical case. Ky et al [33] presented an experimental study of a solar chimney prototype made up of 49 hemispherical concentrators, this collector works according to the theory of hot spots. The resulting temperature profile suggests that the innovation provided could replace flat absorbers, allowing air to circulate more smoothly through the manifold and thereby reducing its surface area. Ahmed et al [34] built two hybrid models of solar chimney designated respectively by (A) and (B). System A consists of a glass collector, a photovoltaic panel acting as an absorber, and a chimney, while system (B) comprises a photovoltaic panel acting as a collector and an absorber in plywood. They obtained the following results: system (A) recorded the highest temperature $\left(90^{\circ} \mathrm{C}\right)$ against $67^{\circ} \mathrm{C}$ for system $(\mathrm{B})$ at noon. The velocity level recorded by system (A) is higher than that of the system (B) because the glass collector increases the absorbed energy. Figure 7 and Figure 8 show respectively system $(\mathrm{A})$ and system $(\mathrm{B})$.

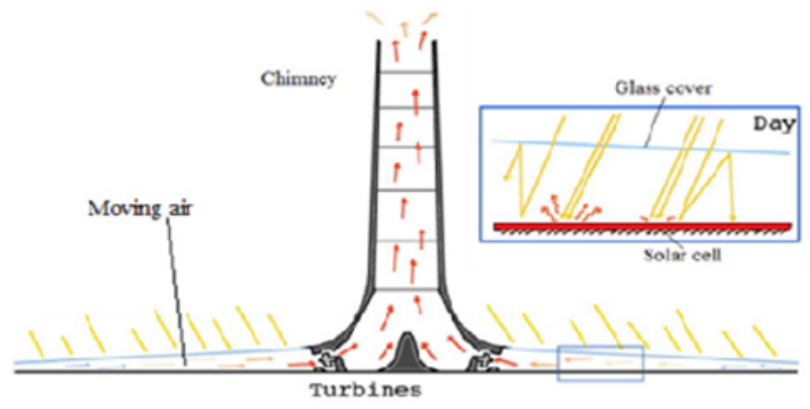

Fig 7. Hybrid gazed PV / solar chimney

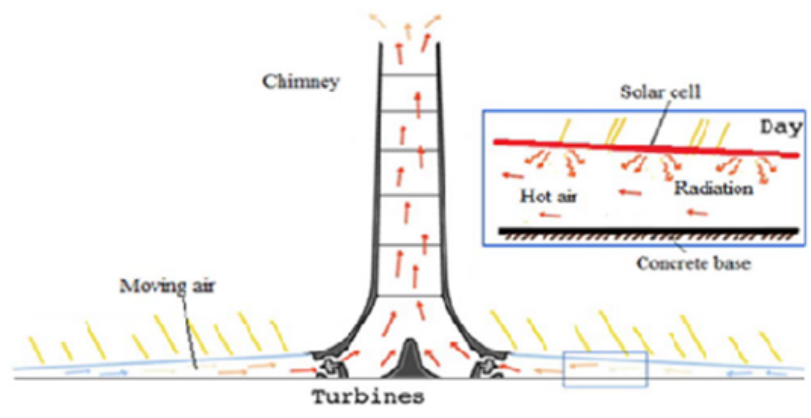

Fig 8. Hybrid PV/solar chimney

Fadaei et al [35] experimentally studied the effect of the latent heat storage of a paraffin phase change material. The results showed that the maximum temperatures and velocities $\left(72^{\circ} \mathrm{C}\right.$ and $\left.2 \mathrm{~m} / \mathrm{s}\right)$ were recorded at the phase change material absorber against the devoid absorber which was recorded $\left(69^{\circ} \mathrm{C}\right.$ and $\left.1.9 \mathrm{~m} / \mathrm{s}\right)$. In the context of thermal building energy, Abdeen et al, Elghamry et al, Hamood et al [36-38], built prototypes for the realization of thermal comfort. Mahal et al [39], developed a hybrid solar chimney system coupled with a liquid desiccation system that could simultaneously produce electricity and freshwater using calcium chloride acting on the air of the prototype. 
The study of experimental models demonstrates the enthusiasm and reliability of the system, hence the numerous numerical studies that have followed.

From the literature review, we distinguish five simple theoretical models compared with the results of the CFD calculation code. These are Chitsomboon et al, Schlaich et al, Tingzhen et al, Zhou et al, Koonsrisuk and Chitsomboon [40-44]. Nevertheless, Mullett [45] began the development of theoretical models of the solar chimney while expressing that the overall efficiency is proportional to the size of the chimney. Schlaich et al [46,47], gave the expression of the flux at the collector outlet and the efficiency of the chimney. Using the Boussinesq approximation, Unger et al [48] gave the expression of the maximum velocity reached in natural convection while Nizetic et al [49] showed the parabolic profile of the velocity at the chimney entrance. Padki and Sherif [50,51] developed models capable of producing significant energies in the medium and long term, Pasumarthi and Sherif [52] introduced two innovations which allowed them to increase the total power output of the chimney. Bernades et al [53] used the numerical CFD (Computational Fluid Dynamic) model in the study of convective flow in a solar chimney. They presented a solution for Navier-Stokes's equations and the energy for a steady-state laminar natural convection, using the finite volume method in generalized coordinates. This method provides a detailed view of the geometric effects and operational, optimal geometric characteristics. Kröger and Blaine [54], Kröger and Buys [55] respectively developed analytical relations to determine the pressure difference due to friction phenomena and heat transfers to develop a radial flow between the roof and the collector. Padki and Sherif [56] established differential equations, the power formula, and the relative efficiency of the solar chimney. Gannon and Von Backström [57] succeeded in predicting the performance of a large-scale power plant. Chitsomboon et al $[58,59,85]$ proposed a model of dimensionless variables which they validated with CFD theory.

Gannon and Von Backström [60-62] with one model of turbine claimed to be able to extract $80 \%$ of the power generated by the flow, then with another type found a total efficiency between 85 and $90 \%$. Bernardes et al [63] showed that the power output can be improved by increasing the height of the chimney, the collector's surface, and its transmittance. Von Backström [64] obtained the average density in the chimney. First, Schlaich et al [65,66,47] gave some results of design, construction, and operation of a prototype like that of Manzanares and proposed commercial prototypes accompanied by basic technical, economic data, then they confirmed that a solar chimney is an option of low-cost electricity production. Finally, they presented a model providing information from a theoretical, practical, experimental, and economic point of view for the design of a 200 MW chimney. Pastohr et al [67[ showed that the stationary solution hypothesis does not consider the heat storage of the soil and the fluid, hence the dynamic regime solution would be of particular interest in the future. Serag-Eldin ${ }^{[68]}$ from the kepsilon model studied the effects of atmospheric winds on the performance of a solar chimney, from which it results in total degradation of the performance in the presence of strong wind and a significant degradation for weak wind, except for sensors with low intake height. Bilgen and Rheault [69] built an inclined collector field at the lower level of a mountain, thus playing the role of a chimney. They developed a mathematical model which results showed that the production of electrical energy can reach $85 \%$ of that produced by a horizontal collector solar chimney. Tingzhen et al [70-73] developed a model which studies the difference in static pressure between the inlet and the outlet of the chimney. They showed that this static pressure is negative and decreases throughout the flow in the collector, but increases inside the chimney, and in another model validated by the data of the Manzanares prototype. They proved that the output power could exceed $10 \mathrm{MW}$. In addition, they concluded that the soil storage energy, velocity, and average chimney outlet temperature increase with increasing incident solar radiation.

Pretorius and Kröger [74,75] developed and improved a mathematical model based on a convective heat transfer equation and the Navier Stock equations. Von Backström and Fluri [76,77] investigated the validity and applicability of the hypothesis that the optimum ratio of turbine pressure drops to potential pressure corresponding to maximum power is $2 / 3$, then they compared the performance of several turbines using analytical models and optimization techniques. Peng et al [78] developed an optimized mathematical model relating to the relative static pressure. Larbi et al [79] in an energy model performance study of a solar chimney showed that the power generated depends on solar radiation, the ambient temperature, the height of the chimney, and the collector's surface. In addition, Chergui et al [80] recommended a thorough investigation of operational and geometric aspects considering meteorological conditions and turbulence. Sangi et al [81] demonstrate that the pressure decreases along with the collector and its minimum value is located at the chimney base when the latter was considered positive and increasing throughout the flow in the manifold by Pastohr et al. Tayebi et al [82-84] present a numerical model of laminar natural convection in a vorticity-current function formulation, they prove that the airflow varies not only with the ground-roof distance of the collector, but also with the Rayleigh number; Atit et al, Ming et al, Putkaradze et al [8587], showed that the geometry of solar chimney constitutes one of the most important parameters of thermo hydrodynamic efficiency. Ghalamchi et al, Kasaeian et al $[88,89]$ carried out the theoretical evaluation of the performance of a solar chimney using FLUENT computer code, then validated their study using an experimental prototype. The considered parameters are related to the collector inclination, the chimney diameter, and the collector inlet height. Guo et al [90] showed that there is a maximum value of the collector radius beyond which the output power remains practically constant. Hakim et al [91] showed 
that the configuration but also the addition of a storage system improved the velocity at the entrance of the chimney. Cottam et al [92] presented a stationary analytical model of several designs of collectors to study their impacts on the performance of the solar chimney. It was found that the segmented profile manifold was the one corresponding to the maximum power with a lower construction cost and able to withstand bad weather. Hu et al [93] established a mathematical model of a solar chimney with a divergent chimney. They showed that many small divergent chimneys gave the same power as long cylindrical chimneys hence their exceptional advantage. Hosseini et al [94] carried out a numerical study of a solar chimney equipped with a longitudinal rectangular fin absorber. They concluded that the discontinuous fin absorber improves the performance of the solar chimney compared to the flat absorber. Hoseini et al [95] presented a numerical analysis of divergent, convergent, and horizontal manifolds. They showed that the divergent-type manifold characterized by high speed and high airflow produced more power than the other two. Toghraie et al [96] indicated that there is an optimal value of the chimney radius for which the power and the efficiency are maximum. Gholamalizadeh et al [97] determined the configuration capable of producing a power of $1 \mathrm{~kW}$ with a radial magnification of 1.5 ; several velocity and temperature profiles corresponding to three different chimney heights for a magnification of 3 were illustrated. Khaoula et al [98] showed that the storage system is the alternative solution to periods of low radiation, thus allowing continuous operation of the plant. They, therefore, suggest acting on the thermal properties of the fluids and solid used, or on the latent or sensible heat of storage, or a combination of the two Parthasarathy et al [99] by improving the design of the absorber observed that the insertion of glazing and fins in the design of the absorber leads to better thermal efficiency in forced convection. Abayomi et al [100] presented a numerical study of a solar chimney integrated into a tropical habitat. The results presented made it possible to rule on the fundamentals of temperature and airflow likely to ensure thermal comfort and produce electricity in the home. Haythem et al [101] proposed a new collector design with a double-pass counter current mode. For this purpose, they compared the conventional collector, the double-pass collector with the parallel flow, and the collector with a double-pass counter-current mode. They came to the result that the collector with a double-pass counter current mode is the one which efficiency increased by $28 \%$ compared to the conventional one.

\section{Mathematical formulation}

We use here the formalism, the heat equation, the vorticity, and the current function by considering the assumption of Boussinesq (We suppose the density constant in all the terms except in the force of gravity). The conservation equations for momentum are then replaced by that of vorticity. The theoretical study is carried out in steady state in an interval corresponding to the minimum and maximum equilibrium temperatures of the absorber, obtained during the experimental study $(320<\mathrm{T}$ $<370) \mathrm{K}^{1}$. Figure 11 shows the movement of the fluid.

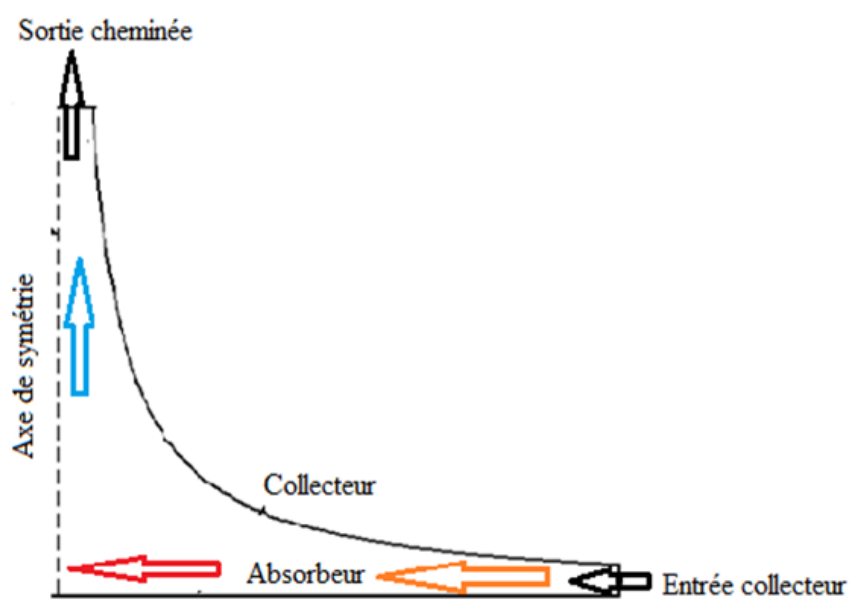

Fig 9. Axisymmetric representation of the optimized solar tower

The following assumptions are considered in this study.

The air follows ideal gas law, permanent two-dimensional laminar regime, physical properties of air are assumed to be constant except density in buoyancy force. The radiation exchange, the viscous heat dissipation and the power density are neglected. Finally, the walls of the chimney are adiabatic with the non-slip condition [102]. 


\section{Mass conservation}

$$
\frac{\partial u}{\partial x}+\frac{\partial v}{\partial y}=0
$$

\section{Vorticity equation}

$$
\frac{\partial(u w)}{\partial x}+\frac{\partial(v w)}{\partial y}=\frac{\partial T}{\partial x}(g \cdot \beta)+v\left(\frac{\partial^{2} \omega}{\partial x^{2}}+\frac{\partial^{2} \omega}{\partial y^{2}}\right)
$$

\section{Energy conservation equation}

$$
u \frac{\partial T}{\partial x}+v \frac{\partial T}{\partial y}=\frac{\lambda}{\rho \cdot C p}\left(\frac{\partial^{2} T}{\partial x^{2}}+\frac{\partial^{2} T}{\partial y^{2}}\right)
$$

\section{Boundary conditions}

The boundary conditions are represented on figure 10 below.

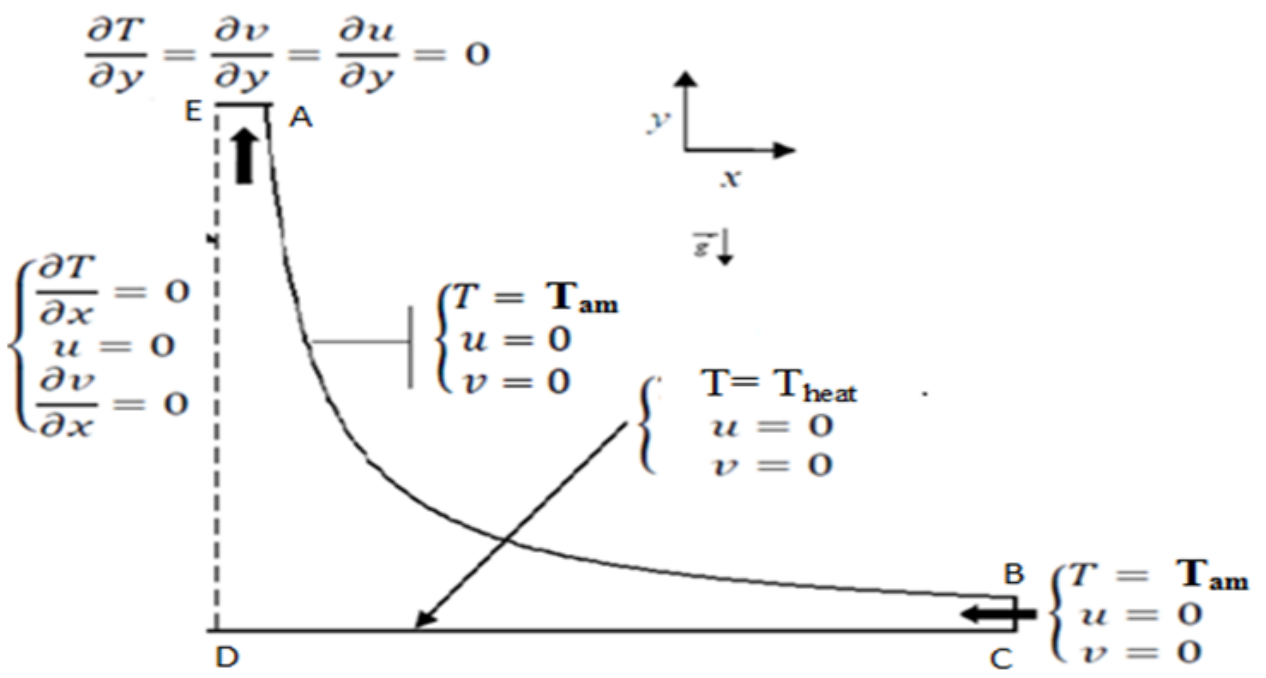

Fig 10. Boundary conditions in axisymmetric solution

Numerical methods present shortcomings in the face of certain geometries, hence the use of the mesh generation technique. According to Hoffmann [103], the basic idea is to transform a complex geometry into a simple geometry by using generalized or hyperbolic coordinates. We are going to transform the cartesian equations into hyperbolic coordinates to formulate with precision the boundary conditions for the selected tower model. The relations allowing the passage from cartesian coordinates $(x, y)$ to hyperbolic coordinates $(\xi, \eta)$ is carried out using the following relations [104]:

$$
\begin{aligned}
& x=\sqrt{\frac{r+\xi}{2}} ; y=\sqrt{\frac{r-\xi}{2}} \\
& \eta=2 x y ; \xi=x^{2}-y^{2} ; r=\sqrt{\xi^{2}+\eta^{2}}=x^{2}+y^{2}
\end{aligned}
$$

Figure 11, Figure 12, and Figure 13 show the coordinate system, the physical domain, and the computation domain. 


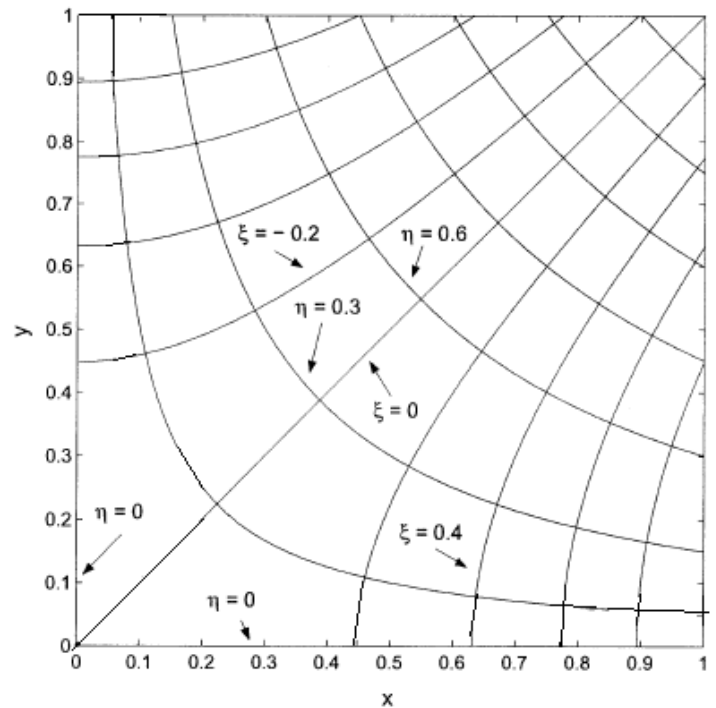

Fig 11. Coordinate system $\eta=2 x y, \xi^{2}=x^{2}-y^{2}$

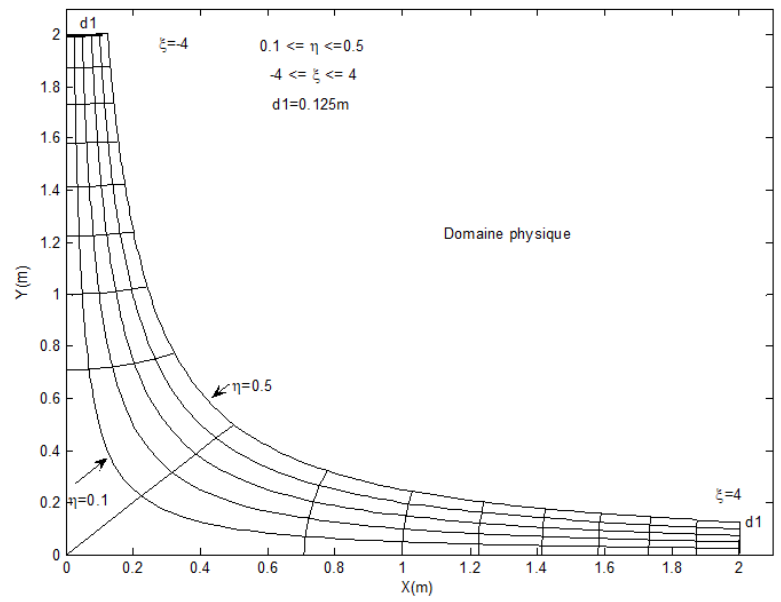

Fig 12. Real physical domain

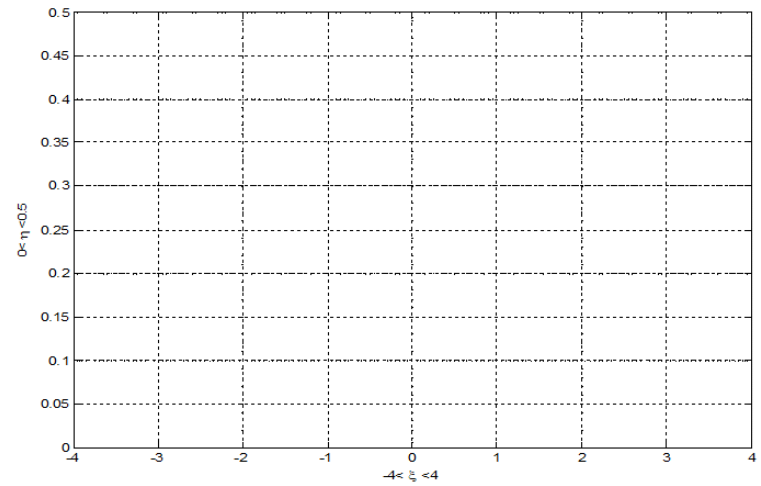

Fig 13. Computation domain 
Equations (1), (2), (3) become:

$$
\begin{aligned}
& \frac{\partial\left(V_{\xi}\right)}{\partial \xi}+\frac{\partial\left(V_{\eta}\right)}{\partial \eta}=0 \\
& V_{\xi} \frac{\partial T}{\partial \xi}+V_{\eta} \frac{\partial T}{\partial \eta}=\frac{1}{h} \frac{\lambda}{\rho \cdot C p}\left(\frac{\partial^{2} T}{\partial \xi^{2}}+\frac{\partial^{2} T}{\partial \eta^{2}}\right) \\
& \frac{V_{\xi}}{h} \frac{\partial w}{\partial \xi}+\frac{V_{\eta}}{h} \frac{\partial w}{\partial \eta}=\frac{v}{h^{2}}\left(\frac{\partial^{2} w}{\partial \xi^{2}}+\frac{\partial^{2} w}{\partial \eta^{2}}\right)+g \beta\left(A(\xi, \eta) \frac{\partial T}{\partial \xi}+B(\xi, \eta) \frac{\partial T}{\partial \eta}\right]
\end{aligned}
$$

\section{Numerical solution}

The resulting equations having been transformed into curvilinear coordinates are subsequently discretized with a finite difference scheme using the Samarsky method [105] exposed in Nogotov book [106] the solutions obtained from the system of dimensional algebraic equations make it possible to generally determine the evolution of the aeraulic parameters. We use a method of dimensional analysis like that used by Tayebi [102] and Heisler [107] but presenting a fundamental difference as to the choice of the characteristic length appearing in the Rayleigh number defined by Tahar [102]

$$
\begin{gathered}
d=H c ; H=h \cdot d=\frac{H c}{2 \sqrt{r}} ; V_{\xi}^{*}=V_{\xi} \cdot \frac{d}{a} ; V_{\eta}^{*}=V_{\eta} \cdot \frac{d}{a} ; \quad \psi^{*}=\frac{\psi}{a} ; w^{*}=\frac{w \cdot d^{2}}{a} \\
\xi^{*}=\frac{\xi}{d^{2}} ; \eta^{*}=\frac{\eta}{d^{2}} ; T^{*}=\frac{T-T_{c}}{T_{\text {heat }}-T_{c}} ; t^{*}=t \frac{a}{d^{2}}
\end{gathered}
$$

$\frac{a}{d}$ characteristic velocity

$\frac{d^{2}}{a}$ Characteristic time

Equations (1), (2), and (3) can be summed up in the equations below, by posing:

$$
\begin{aligned}
& V_{\xi}^{*}=\frac{1}{H} \frac{\partial \psi^{*}}{\partial \eta^{*}} ; V_{\eta}^{*}=-\frac{1}{H} \frac{\partial \psi^{*}}{\partial \xi^{*}} ; R a=\frac{g \beta \Delta T d^{3}}{v a} ; \\
& \operatorname{Pr}=\frac{v}{a} ;\left(v=\frac{\mu}{\rho} ; a=\frac{\lambda}{\rho}\right) \\
& \frac{\partial}{\partial \xi^{*}}\left(\frac{1}{H} \frac{\partial T^{*}}{\partial \xi^{*}}-V_{\xi}^{*} T^{*}\right)+\frac{\partial}{\partial \eta^{*}}\left(\frac{1}{H} \frac{\partial T^{*}}{\partial \eta^{*}}-V_{\eta}^{*} T^{*}\right)=0 \\
& \frac{\partial}{\partial \xi^{*}}\left(\frac{\operatorname{Pr}}{H} \frac{\partial w^{*}}{\partial \xi^{*}}-V_{\xi^{*}} w^{*}\right)+\frac{\partial}{\partial \eta^{*}}\left(\frac{\operatorname{Pr}}{H} \frac{\partial w^{*}}{\partial \eta^{*}}-V_{\eta}{ }^{*} w^{*}\right)=-\operatorname{Pr} \cdot \operatorname{Ra}\left(C\left(\xi^{*}, \eta^{*}\right) \frac{\partial T^{*}}{\partial \xi^{*}}+D\left(\xi^{*}, \eta^{*}\right) \frac{\partial T^{*}}{\partial \eta^{*}}\right) \\
& w^{*}=-\frac{1}{H^{2}}\left(\frac{\partial^{2} \psi^{*}}{\partial \xi^{2}}+\frac{\partial^{2} \psi^{*}}{\partial \eta^{*}}\right)
\end{aligned}
$$

The dimensional boundary conditions are given below:

-Outlet

$$
\frac{\partial T^{*}}{\partial \xi^{*}}=0 T(1, j)=\frac{4 T^{*}(2, j)-T^{*}(3, j)}{3}
$$


-Inlet

$$
T^{*}(N I, j)=0
$$

-The ground

$$
T^{*}(i, j)=0
$$

-Roof

$$
T^{*}(i, j)=0
$$

-Axisymmetric axis

$$
T^{*}(i, 1)=\frac{4 T^{*}(i, 2)-T^{*}(i, 3)}{3}
$$

-Boundary conditions of the stream function

-Outlet

$$
\psi^{*}(1, j)=\frac{8 \psi^{*}(2, j)-\psi^{*}(3, j)}{7}
$$

-Inlet

$$
\psi^{*}(N I, j)=\frac{4 \psi^{*}(N I-1, j)-\psi^{*}(N I-2, j)}{3}
$$

-Roof

$$
\psi^{*}(i, 1)=\frac{4 \psi^{*}(i, 2)-\psi^{*}(i, 3)}{3}
$$

-Axisymmetric axis

$$
\begin{gathered}
\frac{\partial T^{*}}{\partial \xi^{*}}=0 \\
\psi^{*}(i, 1)=\frac{8 \psi^{*}(i, 2)-\psi^{*}(i, 3)}{7}
\end{gathered}
$$

-Boundary conditions of the vorticity equation

-Outlet

$$
\omega^{*}(1, j)=-\frac{1}{H^{2}}\left(\frac{7 \psi^{*}(1, j)-8 \psi^{*}(2, j)+\psi^{*}(3, j)}{2 D \xi^{*^{2}}}\right]
$$

-Inlet

$$
\omega^{*}(N I, j)=-\frac{1}{H^{2}}\left(\frac{7 \psi^{*}(N I, j)-8 \psi^{*}(N I-2, j)+\psi^{*}(N I-3, j)}{2 * D \xi^{* 2}}\right)
$$

-Axisymmetric axis

$$
\omega^{*}(i, 1)=0
$$

-Velocity boundary conditions

-Outlet

$$
V^{*}(1, j)=\frac{4 V^{*}(2, j)-V^{*}(3, j)}{3}
$$




$$
U^{*}(1, j)=0
$$

-Inlet

$$
\begin{aligned}
& U^{*}(N I, j)=0 \\
& V^{*}(N I, j)=0
\end{aligned}
$$

-Ground

$$
\begin{aligned}
& U^{*}(i, j)=0 \\
& V^{*}(i, j)=0
\end{aligned}
$$

-Roof

$$
\begin{gathered}
U^{*}(i, j)=0 \\
V^{*}(i, j)=0
\end{gathered}
$$

Axisymmetric axis

$$
\begin{gathered}
U^{*}(i, j)=\frac{4 V^{*}(i, 2)-V^{*}(i, 3)}{3} \\
U^{*}(i, 1)=0
\end{gathered}
$$

For the resolution we use the so-called integro-interpolation method described by Nogotov [106], a system of differential equations is obtained by integration of the system constituted by equations (12) to (13). Our calculation program gives the following results.

\section{Results and discussion}

\subsection{Temperature evolution in the collector}

Figure 14 presents the temperature evolution in the collector.

From the dimensionless study, the fluid temperature in the collector increases very quickly along the $\mathrm{x}$-axis, as the radius decreases. At the chimney inlet, we notice a slight decrease in temperature. This has also been observed by Ghalamchi [31]. This is in fact the area where heat energy is transformed into kinetic energy in the chimney. The increase in the Rayleigh number generally leads to an intensification of convective movements in the ducts.

\subsection{Velocity evolution in the collector}

The velocity evolution shown in Figure 15 increases in the collector when one moves in the direction of radius decrease. But we notice that the slope of the curve is more pronounced near the base of the chimney. In fact, the fluid having acquired maximum energy is no longer confined and can then move by free convection in the chimney. 


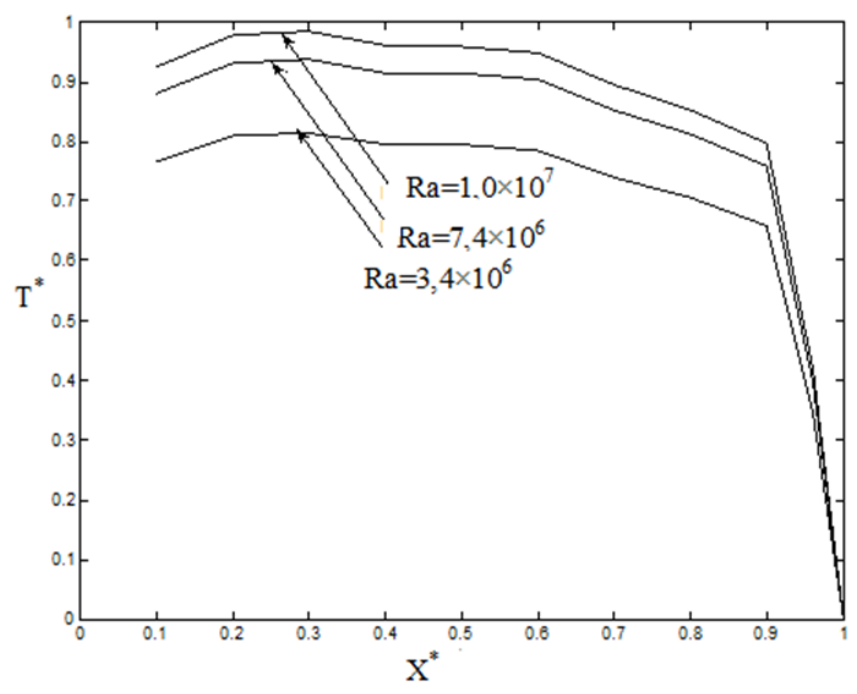

Fig 14. Temperature evolution in the collector near theabsorber

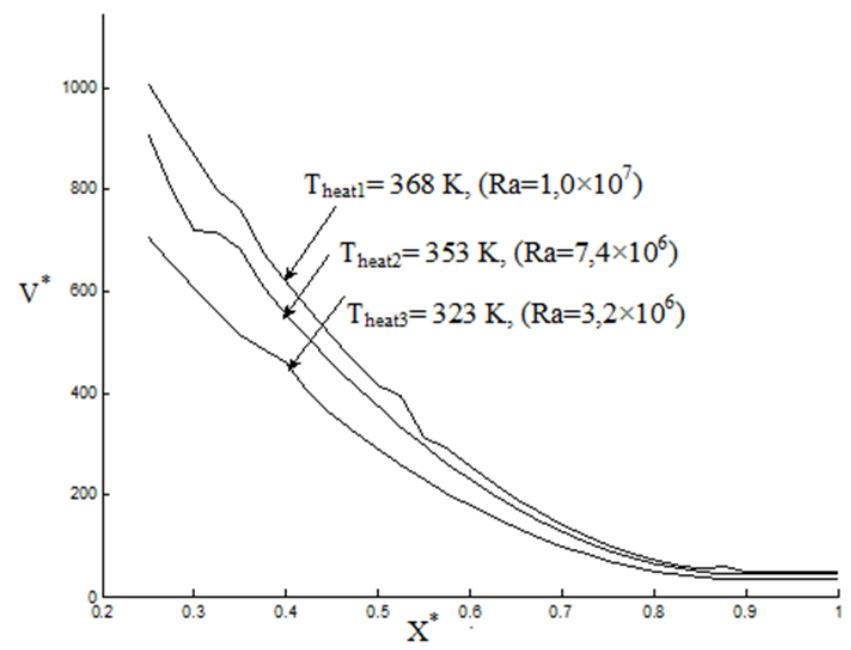

Fig 15. Fluid velocity evolution in the collector as afunction of $X^{\star}$ for different Rayleigh numbers

\section{Fluid temperature evolution in the chimney}

Figure 16 and Figure 17 show respectively the fluid temperature evolution in the chimney and in a cross-section. The fluid temperature evolution in the chimney naturally shows an almost hyperbolic profile. In fact, the base of the chimney receives hot air when it has acquired the maximum energy, leading to the highest temperature at the base. This then decreases very quickly. In the laminar regime, for $10^{6}<\mathrm{Ra}<10^{7}$, outlet temperatures remain close to ambient temperature as depicted in Figure 16. Figure 17 shows a parabolic profile of the transverse temperature distribution within the chimney when it is assumed that the walls are at a constant temperature.

\subsection{Evolution of the fluid velocity in the chimney}

Figure 18 shows the velocity evolution in the chimney. In the variation interval chosen for the Rayleigh numbers $\left[10^{6}, 10^{7}\right]$, the maximum velocities are always observed between $0.2<\mathrm{X} *<0.4$ for the chosen geometry as in Figure 18. Heisler [107] and Tahar [102] place this zone close to 0.2 for Rayleigh's number of the order of $10^{5}$. It is therefore the preferred zone for turbines installation. We can notice that the Rayleigh numbers chosen and represented in Figure 18 correspond to the temperatures that 


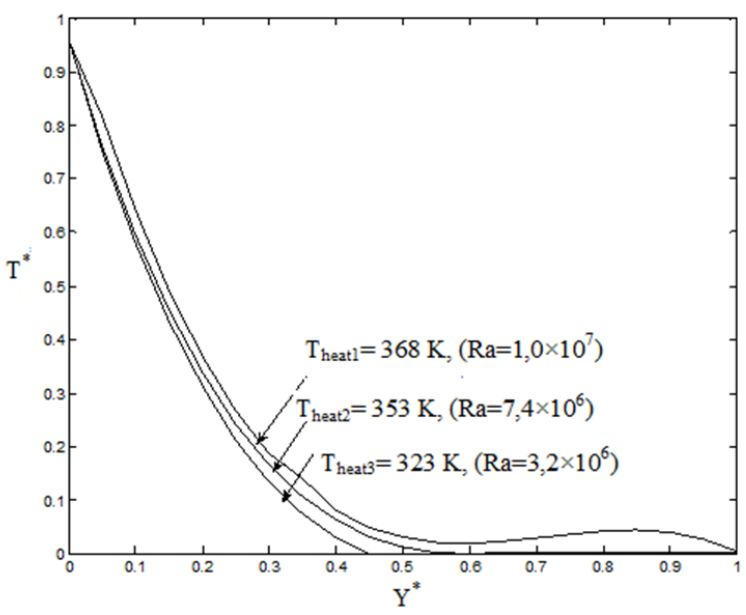

Fig 16. Dimensional evolution of the temperature in the chimney

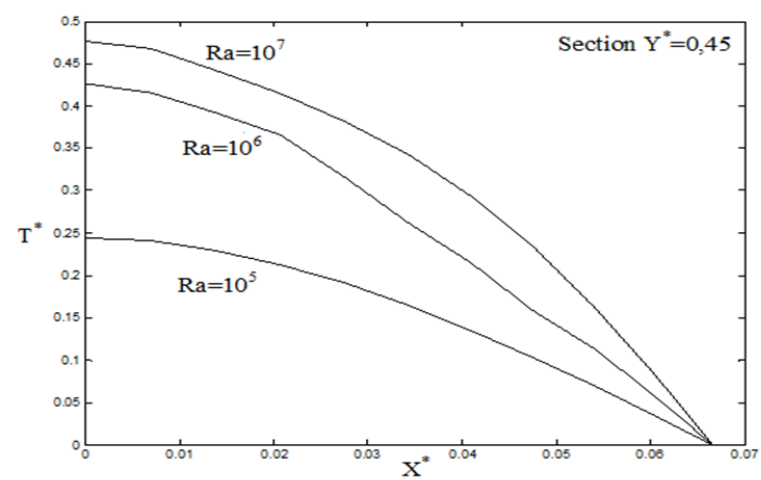

Fig 17. Evolution of the temperature in a cross-section of the chimney $\mathrm{Y}^{*}=0.45$

are usually noted in the vicinity of the absorbers, in our climate, during a day.

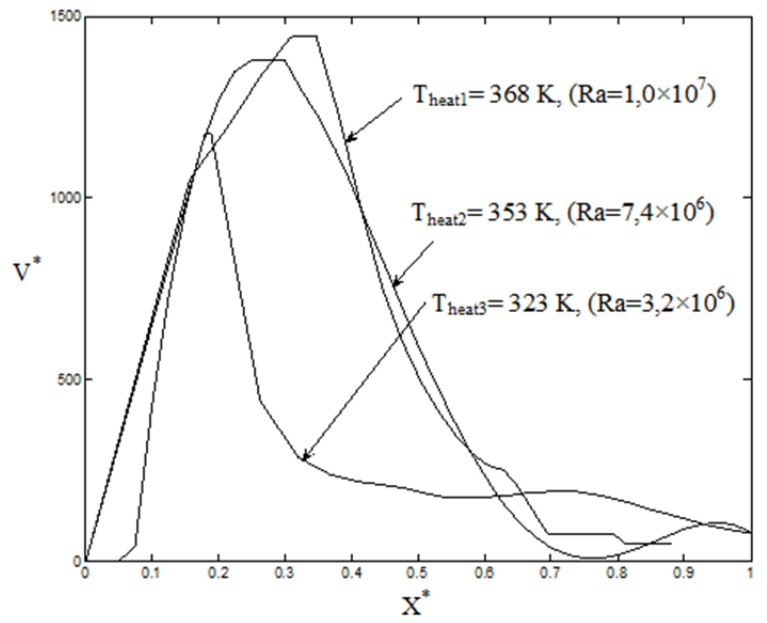

Fig 18. Evolution of the fluid velocity in the chimney as a function of $\mathrm{X}^{\star}$ for different Rayleigh numbers 


\section{Conclusion}

The aeraulic parameters evolution is simulated using curves showing an acceptable precision, of the order of $4 \%$, for temperatures, however, those concerning the velocities are less precise ( $>10 \%)$ The solutions obtained from the system of dimensionless equations allowed us to determine:

The spatial evolution of temperatures and velocities in the collector for different Rayleigh numbers.

An increase in Rayleigh numbers leads to an intensification of convection movements in the collector and an increase in the fluid temperature. The maximum velocities concentration region hardly varies as a function of the Rayleigh number. The temperatures close to the entrance of the chimney are decreasing slightly using our calculation code.

Spatial evolution of temperatures and velocities in the chimney for different Rayleigh numbers.

The velocity curves in the chimney, a bell curve in the vicinity of the inlet, obtained using our calculation program are in perfect agreement with the literature data. This is the sensitive area that must be determined with precision to place a turbine or drying racks. However, this first approach, using our calculation program, makes it possible to pre-dimension a system using the calculation of its aeraulic parameters.

\section{References}

1. Moctar O, Boureima D, Sié K, Amadou K, Ky T, Bathiebo D J. Experimental study, in natural convection. Global journal of pure and applied sciences. 2015; 21, 155-169.

2. Haaf W, Friedrich K, Mayr G, Schlaich J. Solar Chimneys. Part I: Principle and construction of the pilot plant in Manzanares. International Journal of Solar Energy. 1983; 2(1), 3-20. https://doi.org/10.1080/01425918308909911

3. Bernardes MA dos S. Solar Chimney Power Plants - Developments and Advancements, Solar Energy, Radu D Rugescu (Ed.), ISBN: 978-953-307-052-0, InTech, (2010). Available from: http://www.intechopen.com/books/solar-energy/solar-chim ney-power-plants-developments-and-advancements.

4. Dhahri A, Omri A. A Review of solar Chimney Power Generation Technology. International Journal of Engineering and Advanced Technology (IJEAT). 2013; 2(3), ISSN: 2249 - 8958.

5. Haaf W, Solar chimneys. Part II: Preliminary test results from the Manzanares pilot plant. International Journal of Solar Energy, 1984; 2(2), 141-161. https://doi.org/10.1080/01425918408909921

6. Schlaich, J. Tension structures for solar electricity generation. Engineering structures. 1999; 21(8), 658 - 668. https://doi.org /10.1016/S0141-0296(98)00021-2

7. Pasumarthi N, Sherif S A. Experimental and theoretical performance of a demonstration solar chimney model. Part II: Experimental and theoretical results and economic analysis, International Journal of Energy Research, 1998; 22(5), 443-461.h ttps://doi.org/10.1002/(SICI)1099-114X(199804)22:5<443::AID-ER381>3.0.CO;2-V.

8. Pasumarthi N, Sherif S. A. Experimental and theoretical performance of a demonstration solar chimney model. Part I: mathematical model development. International Journal of Energy Research. 1998. 22(3), 277-288. https://doi.org/10.1002/(S ICI) 1099-114X(19980310)22:3<277::AID-ER380>3.0.CO;2-R

9. Zhou X, Yang J, Xiao B, Hou G. Simulation of a pilot solar chimney thermal power generating equipment. Renewable energy, 2007; 32(10),1637-1644. https://doi.org/10.1016/j.renene.2006.07.008

10. Zhou X, Yang J, Xiao B, Hou G. Experimental Study of the temperature field in a solar chimney power setup. Applied Thermal Engineering. 2007; 27, 2044-2050. https://doi.org/10.1016/J.APPLTHERMALENG.2006.12.007

11. Ferreira A G, Maia C B, Cortez M F B, Valle R M. Technical feasibility assessment of a solar chimney for food drying, Solar Energy, 2008; 82(3), 198-205. DOI : 10.1016/j.solener.2007.08.002

12. Maia C B, Ferreira A G, Valle R M, Cortez M F B. Theoretical evaluation of the influence of geometric parameters and materials on the behavior of the airflow in a solar chimney. Computers and Fluids. 2009; 38(3), 625-636. DOI: 10.1016/j.compfluid.2008.06.005

.13. Maia C B, Ferreira A G, Valle R M, Cortez M F B. Analysis of the airflow in a prototype of a solar chimney dryer. Heat Transfer Engineering, 2009; 30(5), 393-399. DOI: 10.1080/01457630802414797

14. Koyun A, Üçgül I, Acar, M, Şenol, R, Günes R. Bacasısisteminintermalözetdizaynı, tesisatmülhendisliğidergisi. 2007; (98), 45-50. http:// www.mmoistanbul.org/yayin/tesisat/98/6.

15. Golder K. Combined solar pond and solar chimney. Final year mechanical engineering project. School of aerospace, mechanical and manufacturing engineering, 2003; Bundoora campus, RMIT University, Melbourne, Australia.

16. Akbarzadeh A, Johnson P, Singh R. Examining potential benefits of combining a chimney with a salinity gradient solar pond for production of power in salt affected areas. Solar Energy, 2009; 83(8), 1345-1359. DOI:10.1016/j.solener.2009.02.010 17. Ahmed S T, Chaichan M T. A Study of free convection in a solar chimney model. Engineering and Technological Journal, 
2011; 29(14), 2986-2997.

18. Buğutekin A, An experimental investigation of the effect of periphery height and ground temperature changes on the solar chimney system. Journal of Thermal Science and Technology, 2012; 32(1), 51-58, ISSN 1300-3615.

19. Najmi M, Nazari A, Mansouri H, Zahedi G, Feasibility study on optimization of a typical solar chimney power plant, Heat Mass Transfer, 2012; 48(3), 475-485. DOI: 10.1007/s00231-011-08945

20. Kasaeian A B, Heidari E, Vatan Sh N. Experimental investigation of climatic effects on the efficiency of a solar chimney pilot power plant. Renewable and Sustainable Energy Reviews. 2011; 15(9), 5202-5206. https://doi.org/10.1016/j.rser.2011.04. 019.

21. Mehla N, Makade R, Thakur N S. Experimental analysis of a velocity field using variable chimney diameter for solar updraft tower. International Journal of Engineering Science and Technology, 2011; 3(4), 3167-3171. ISSN: 0975-5462.

22. Shuia E M, Arebi B H, Abuashe I A. Experimental and Theoretical Investigation of Performance of a Solar Chimney Model, Part I: Experimental Investigation. Solar energy and sustainable development. 2014; 3(1), 1-12.

23. Al-Dabbas M A. The first pilot demonstration: solar updraft tower power plant in Jordan, International Journal of Sustainable Energy, 2012; 399-410, 31(6) DOI: 10.1080/1478646X.2011.589516.

24. Chappell R D, Congdon M J, French J J. Design, construction, and testing of a small-scale solar chimney for nomadic herdsmen. 2012; ASME 2012 6th International Conference on Energy Sustainability. San Diego, California, USA, 33-38. https ://doi.org/10.1115/ES2012-91194.

25. Koonsrisuk A, Analysis of flow in solar chimney for an optimal design purpose, Thesis, 2009; Suranaree University of Technology.

26. Aja O C, Al-Kayiem H H, Abdul Karim Z A. Experimental investigation of the effect of wind speed and wind direction on a solar chimney power plant. Conference: WIT Transactions on Ecology and the Environment. 2013; 945-955., 179. DOI: $10.2495 / \mathrm{SC} 130802$.

27. Al-Azawiey SS, Hassan SB. Heat Absorption Properties of Ground Material for Solar Chimney Power Plants. International Journal of Energy Production and Management. 2016; 1(4): 403-418. DOI: 10.2495/EQ-V1-N4-403-418

28. Li Y, Liu S. Experimental study on thermal performance of a solar chimney combined with PCM. Applied Energy. 2014; 114(C), 172-178. DOI: 10.1016/j.apenergy.2013.09.022.

29. Tan AYK, Wong NH. Influences of ambient air speed and internal heat load on the performance of solar chimney in the tropics. Solar Energy. 2014; 102, 116-125. https://doi.org/10.1016/j.solener.2014.01.023

30. Shahreza A R, Imani H. Experimental and numerical investigation on an innovative solar chimney. Energy Conversion and Management. 2015; 95, 446-452. DOI: 10.1016/j.enconman.2014.10.051

31. Ghalamchi M, Kasaeian A, Ghalamchi M. Experimental study of geometrical and climate effects on the performance of a small solar chimney. Renewable and Sustainable Energy Reviews, 2015;43, 425-431. https://doi.org/10.1016/j.rser.2014.11.06 8

32. Okada S, Uchida T, Karasudani T, Ohya Y. Improvement in Solar Chimney Power Generation by Using a Diffuser Tower. Journal of Solar Energy Engineering. 2015; 137(3), 0310091-0310098. DOI: 10.1115/1.4029377.

33. Ky T S M, Ouedraogo S, Ouedraogo A, Boureima D, Moctar O, Bathiebo D J. Novel convection process: Experimental study of a solar chimney with its collector made of hemispherical concentrators. International Journal of Engineering Sciences \& Research Technology 2018; 7(10), 83-96. DOI: 10.5281/zenodo.1471587.

34. Ahmed OK, Hussein A. New design of solar chimney (case study). Thermal Engineering, 2018; 11(C), 105-112. DOI: 10.1016/j.csite.2017.12.008.

35. Fadaei N, Kasaeian A, Akbarzadeh A, Hashemabadi S H. Experimental investigation of solar chimney with phase change material (PCM). Renewable energy, 2018; 123, 26-35. https://doi.org/10.1016/j.renene.2018.01.122.

36. Abdeen A, Serageldin AA, Ibrahim M GE, El-Zafarany A, Ookawara S, Murata R. Solar chimney optimization for enhancing thermal comfort in Egypt: An experimental and numerical study. Solar Energy, 2019; 180, 524-536. https://doi.org/10.1016/j.s olener.2019.01.063.

37. Elghamry R, Hassan H. An experimental work on the impact of new combinations of solar chimney, photovoltaic and geothermal air tube on building cooling and ventilation. Solar Energy. 2020; 205, 142-153. https://doi.org/10.1016/j.solener.2 020.05.049.

38. Hamood B A, Nima M A R. Experimental investigation of thermal performance of a solar chimney provided with a porous absorber plate. Journal of Engineering. 2020; 26(4), 1-20. DOI: https://doi.org/10.31026/j.eng.2020.04.01.

39. Mahal S, Alimin A J. Experimental investigation on a novel integrated solar chimney and liquid desiccant system for simultaneous power and freshwater generation. International Energy Journal. 2020; 20(1), 67 - 86. www.rericjournal.ait.ac.th l. 
40. Chitsomboon T. A validated analytical model for flow in solar chimney. International Journal of Renewable Energy Engineering. 2000; 3(2): 339-346.

41. Schlaich J, Bergermann R, Schiel W, Weinrebe G. Design of commercial solar updraft tower systems - Utilization of solar induced convective flows for power generation. Journal of Solar Energy Engineering. 2005; 127(1), 117-124. DOI: $10.1115 / 1.1823493$

42. Tingzhen M, Wei L, Guoliang X. Analytical and numerical investigation of the solar chimney power plant systems. International Journal of Energy Research. 2006; 30, 861-873. https://doi.org/10.1002/er.1191.

43. Zhou X, Yang J, Xiao B, Hou G, Xing F. Analysis of chimney height for solar chimney power plant. Applied Thermal Engineering, 2009; 29, 178-185. DOI:10.1016/J.APPLTHERMALENG.2008.02.014

44. Koonsrisuk A, Chitsomboon T. A single dimensionless variable for solar chimney power plant modeling. Solar Energy. 2009; 83(12), 2136-2143. https://doi.org/10.1016/j.solener.2009.07.015.

45. Mullet L B. The solar chimney. Overall efficiency, design, and performance. International Journal of Ambient Energy, 1987; 8(1), 35-40. https://doi.org/10.1080/01430750.1987.9675512

46. Schlaich J. Tension structures for solar electricity generation. Engineering structures. 1999; $21(8), 658$ - 668. DOI:10.1016/s0141-0296(98)00021-2.

47. Schlaich J, Bergermann R, Schiel W, Weinrebe G. Design of commercial solar updraft tower systems - Utilization of solar induced convective flows for power generation. Journal of Solar Energy Engineering, 2005; 127(1), 117-124 DOI: $10.1115 / 1.1823493$

48. Unger J, Konvektionsströmungen B G T. Journal of Applied Mathematics and Mechanics. 1988; 69(11). DOI: 10.1002/zamm.19890691127.

49. Nizetic S, Klarin B. A simplified analytical approach for evaluation of the optimal ratio of pressure drop across the turbine in solar chimney power plants. Appl Energy; 2010; 87(2), 587-591. DOI: 10.1016/j.apenergy.2009.05.019

50. Padki M M, Sherif S A. Solar chimney for medium-to-large scale power generation, Proceedings of the Manila International symposium on the development and management of energy resources, 1, 1989; 432-437. Manila, Philippines.

51. Padki M M, Sherif S A. A mathematical model for solar chimneys, paper presented at Proceedings of the 1992 International Renewable Energy Conference, in Renewable Energy: Research and Applications, 1992; University of Jordan, Faculty of Engineering and Technology, Amman, Jordan, June 22-26.

52. Pasumarthi N, Sherif S A. Experimental and theoretical performance of a demonstration solar chimney model - Part I: Mathematical model development, International Journal of Energy Research, 1998; 22(3), 277-288. https://doi.org/10.1002/(S ICI)1099-114X(19980310)22:3<277::AID-ER380>3.0.CO;2-R

53. Bernardes M A dos S, Valle R M, Cortez M F B. Numerical analysis of natural laminar convection in radial solar heater. International Journal of Thermal Science. 1999; 38(1), 42-50. https://doi.org/10.1016/S0035-3159(99)80015-4

54. Kröger D G, Blaine D. Analysis of the driving potential of a solar chimney power plant, R \& D Journal. 1999; 15 (3), 85-94. 55. Kröger D G, Buys J D. Radial flow boundary layer development analysis, R \& D Journal. 1999; 15, 95-102.

56. Padki M M, Sherif S A. On a simple analytical model for solar chimneys. International Journal of Energy Research. 1999; 23(4), 345-349.https://doi.org/10.1002/(SICI)1099-114X(19990325)23:4<345::AID-ER485>3.0.CO;2-Z

57. Gannon A J, Von Backström T W. Solar chimney cycle analysis with system loss and solar collector performance. Journal of Solar Energy Engineering. 2000. 122(3), 133-137. DOI: 10.1115/1.1314379

58. Koonsrisuk, A, Chitsomboon, T, Frictional effect on the flow in a solar chimney. Proceedings of the 4th national symposium on graduate research, Chiang Mai, Thailand. 2004.

59. Koonsrisuk A, Chitsomboon T. Dynamic similarity in solar chimney modeling. Solar Energy, 2007; 81, 1439-1446. https:/ /doi.org/10.1016/j.solener.2007.03.00

60. Gannon A J, Von Backström T W. Solar chimney turbine part 1 of 2: design, paper presented at International Solar Energy Conference, 2002a; 335-341.Reno, NV.

61. Gannon A J, Von Backström T W. Solar chimney turbine part 2 of 2: experimental results, paper presented at International Solar Energy Conference, 2002b; 343-349. Reno, NV.

62. Gannon A J, Von Backström T W. Solar chimney turbine performance, Journal of Solar Energy Engineering, 2003; transactions of the ASME, 125(1), 101-106.

63. Bernardes M A dos S, Weinrebe A Vob G. Thermal, and technical analyses of solar chimneys. Solar Energy, 2003; 75, 511-524. Doi: 10.1016/j.solener.2003.09.012

64 Von Backström T W. Calculation of pressure and density in solar power plant chimneys. Journal of Solar Energy Engineering, 2003; transactions of the ASME, 125(1), 127-129. https://doi.org/10.1115/1.1530198

65. Sclaich J, Bergermann R, Schiel W, Weinrebe G. Design of commercial solar tower systems. Utilization of solar induced 
convective flows for power generation, paper presented at International Solar Energy Conference, Hawaii, 2003; 15-18 March. 66. Sclaich J, Bergermann R, Schiel W, Weinrebe G. Sustainable electricity generation with solar updraft towers. Structural engineering international: Journal of the international association for bridge and structural engineering (IABSE), 2004; 14(3), 225-229. https://doi.org/10.2749/101686604777963883.

67. Pastohr H, Kornadt O, Gürlebeck K. Numerical and analytical calculations of the temperature and flow field in the upwind power plant. International Journal of Energy Research, 2004; 28(6), 495-510. DOI: 10.1002/er.978.

68. Serag-Eldin M A. Computing flow in a solar chimney plant subject to atmospheric winds, paper presented at proceedings of the ASME Heat Transfer/Fluids Engineering summer conference 2004; HT/FED 2004, Charlotte, NC. 1153-1162 https://do i.org/10.1115/HT-FED2004-56651

69. Bilgen E, Rheault J. Solar chimney power plants for high latitudes. Solar Energy, 2005; 1-10. DOI:10.1016/J.SOLENER.2005.01.003

70. Tingzhen M, Wei L, Guoliang X. Analytical and numerical investigation of the solar chimney power plant systems. International Journal of Energy Research, 2006; 30(11), 861-873. https://doi.org/10.1002/er.1191.

71. Tingzhen M, Wei L, Guoliang X, Yanbin X, Xuhu G, Yuan P. Numerical simulation of the solar chimney power plant systems coupled with turbine. Renewable Energy, 2008; 33, 897-905. doi.org/ 10.1016/j.renene.2007.06.021.

72. Tingzhen M, Wei L, Guoliang X, Yuan P. Numerical analysis of flow and heat transfer characteristics in solar chimney power plants with energy storage layer, Energy Conversion and Management, 2008a; 49(10), 2872-2879. DOI: https://doi.org/ 10.1016/J.ENCONMAN.2008.03.004

73. Tingzhen M, Wei L, Guoliang X. Analytical and numerical investigation of the solar chimney power plant systems. International Journal of Energy Research; 2006; 30, 861-873

https://doi.org/10.1002/er.1191

74. Pretorius J P, Kröger D G. Thermo-economic optimization of a solar chimney power plant. Journal of solar energy engineering, 2008; 130(2). DOI: 10.1115/1.2840571

75. Pretorius J P, Kröger D G. Solar chimney power plant performance, Journal of Solar Energy Engineering, 2006; 128(3), 302-311. https://doi.org/10.1115/1.2210491

76. Von Backström T W, Fluri T P. Maximum fluid power condition in solar chimney power plants. An analytical approach. Solar Energy. 2006; 80(11), 1417-1423. DOI: 10.1016/J.SOLENER.2006.04.001

77. Fluri T P, Von Backström T W. Comparison of modelling approaches and layouts for solar chimney turbines, Solar Energy. 2008; 82(3), 239-246. https://doi.org/10.1016/j.solener.2007.07.006.

78. Peng W, Ming T, Lui W, Xu G. Research of the optimization on the geometric dimensions of the solar chimney power plant systems, Huazhong Keji DaxueXuebao (ZiranKexue Ban)/Journal of Huazhong University of science and technology 2007; (Natural Science Edition). https://www.researchgate.net/publication/292123182.

79. Larbi S, Bouhdjar A, CherguiT. Performance analysis of a solar chimney power plant in the southwestern region of Algeria. Renewable and Sustainable Energy Reviews, Elsevier. 2009; 14(1), 470-477. DOI:10.1016/j.rser.2009.07.031

80. Chergui T, Boualit AH, Larbi S, Bouhdjar A. Finite element analysis of laminar flow in solar chimney. Séminaire International sur le Génie Climatique et l'Energétique, SIGCLE. 2010.

81. Sangi R, Amidpour M, Hosseinizadeh B. Modeling, and numerical simulation of Solar chimney power plants. Solar Energy, 2011; 85(5), 829-838. https://doi.org/10.1016/j.solener.2011.01.011

82. Tayebi T, Mahfoud D. Numerical simulation of natural convection in a solar chimney. International Journal of Renewable Energy Research, 2012; 2(4), 712-717.

83. Tayebi T, Djezzar M. Numerical analysis of flows in a solar chimney power plant with a curved Junction. International Journal of Energy Science (IJES). 2013; 3(4). www.ijesci.org.

84. Tayebi T, Djezzar M. Effect of varying ambient temperature and solar radiation on the flow in a solar chimney collector. International Journal of Smart Grid and Clean Energy, 2016; 5(1), 16-23. DOI: 10.12720/sgce.5.1.16-23

85. Atit K, Tawit C. Effects of flow area changes on the potential of solar chimney power plants. Energy, Elsevier. 2013; 51(C), 400-406. DOI: 10.1016/j.energy.2012.12.051

86. Ming T, De Richter R K, Meng F, Pan Y, Liu W. Chimney shape numerical study for solar chimney power generating systems. International. Journal of Energy Research. 2013; 37(4), 310-322. https://doi.org/10.1002/er.1910.

87. Vakhtang P, Peter V, Andrea M, Nima F. Inflatable free-standing flexible solar towers. Solar Energy, 2013; 98, 85-98. DOI: 10.1016/j.solener.2013.07.010

88. Ghalamchi M, Ghalamchi M, Ahanj T. Numerical simulation for achieving optimum dimensions of a solar chimney power plant. Sustainable Energy, 2013; 1(2): 26-31. DOI: 10.12691/rse-1-2-3

89. Kasaeian A, Ghalamchi M, Ghalamchi M. Simulation, and optimization of geometric parameters of a solar chimney in 
Tehran. Energy Conversion and Management. 2014; 83, 28-34. https://doi.org/10.1016/j.enconman.2014.03.042

90. Peng-Hua G, Yin LJ, Yuan W. Numerical simulations of solar chimney power plant with radiation model. Renewable Energy. 2014; 62, 24-30. DOI: 10.1016/j.renene.2013.06.039

91. Semai H, Amor Bouhdjar A, Larbi A. Canopy slope effect on the performance of the solar chimney power plant. International Journal of Green Energy, 2016; 14(3), 229-238. https://doi.org/10.1080/15435075.2016.1253580.

92. Cottam PJ, Duffour P, Lindstrand P, Fromme P. Effect of canopy profile on solar thermal chimney performance. Solar energy. 2016; 129, 286-296. https://doi.org/10.1016/j.solener.2016.01.052

93. Hu S, Leung D YC. Mathematical modelling of the performance of a solar chimney power plant with divergent chimneys. Energy Procedia. 2017; 110, 440-445. DOI: 10.1016/j.egypro.2017.03.166

94. Hosseini S S, Ramiar A, Ranjbar A. Numerical investigation of rectangular fin geometry effect on solar chimney. Energy and Buildings. 2017; 155, 296-307. DOI:10.1016/J.ENBUILD.2017.09.017

95. Hoseini H, Mehdipour R. Evaluation of solar-chimney power plants with multiple-angle collectors. Journal of computational and applied research in mechanical engineering. 2018; 8(1), 85-96. Doi: 10.22061/JCARME.2017.2282.1213.

96. Davood T, Amir K, Masoud A, Arash K. Effect of geometric parameters on the performance of solar chimney power plants. Energy. 2018; 162, 1052-1061. DOI: 10.1016/j.energy.2018.08.086

97. Gholamalizadeh E, Chung J. Parametric study of a pilot SCPP using CFD, Environmental Science, computer Science. IEEE Access, 2018; 6, 19. DOI:10.1109/ACCESS.2018.2875411

98. Khaoula I, Larbi S. Energy performance analysis of a solar chimney power plant with and without thermal storage system. International journal of control, energy, and electrical engineering (CEEE), 2019; 11, 1-7. ISSN 2356-5608.

99. Parthasarathy P, Pambudi N. Performance study of a solar chimney air heater. Case Studies in Thermal Engineering. 2019; 1-7. https://doi.org/10.1016/j.csite.2019.100437.

100. Layeni AT, Waheed MA, Adewumi BA, Bolaji BO, Nwaokocha CN, Giwa SO. Computational modelling, and simulation of the feasibility of a novel dual-purpose solar chimney for power generation and passive ventilation in buildings. Scientific African. 8, 2020; 1-13. https://doi.org/10.1016/j.sciaf.2020.e00298.

101. Haythem N, Zied D, Hedi K. Novel collector design for enhancing the performance of solar chimney power plant. Renewable energy. $2020 ; 145,1658-1671$. https://doi.org/10.1016/j.renene.2019.07.062.

102. Tayebi T. Processus de la convection naturelle laminaire dans une tour solaire. Magistère en Physique. Université Mentouri Constantine, Faculté des sciences exactes, département de physique.2010.

103. Hoffmann K A, Chieng S T. Computational fluid dynamics. 2000; 1, fourth edition.

104. Stocker R, Hosoi A E. Corner flow in free liquid films. Journal of Engineering Mathematics, Kluwer Academic Publishers. 2004; 50:267-288.

105. Samarsky A A. Lectures on the theory of finite difference schemes (Russian), M.1969.

106. Nogotov E F, Berkovsky B M, Minkowycz W J. Applications of numerical heat transfer. McGraw-Hill Book Company, UNESCO, Paris. 1978.

107. Heisler E M. Exploring alternative designs for solar chimneys using computational fluid dynamics. Master of Science in mechanical engineering, Blacksburg, VA.2014, 1-90 